\title{
Addressing Opioid Misuse and Abuse through Interprofessional Engagement and Education
}

\author{
Marta J. Brooks \\ Regis University, mbrooks008@regis.edu \\ Suzanne E. Holm \\ Regis University, sholm001@regis.edu \\ Shelene Thomas \\ Regis University, sthomas@regis.edu \\ Amy J. Rich \\ Regis University, arich002@regis.edu
}

Follow this and additional works at: https://nsuworks.nova.edu/ijahsp

Part of the Counseling Commons, Interprofessional Education Commons, Nursing Commons, Occupational Therapy Commons, Pharmacy and Pharmaceutical Sciences Commons, and the Physical Therapy Commons

\section{Recommended Citation}

Brooks MJ, Holm SE, Thomas S, Rich AJ. Addressing Opioid Misuse and Abuse through Interprofessional Engagement and Education. The Internet Journal of Allied Health Sciences and Practice. 2018 Jan 01;16(1), Article 9.

This Case Study is brought to you for free and open access by the College of Health Care Sciences at NSUWorks. It has been accepted for inclusion in Internet Journal of Allied Health Sciences and Practice by an authorized editor of NSUWorks. For more information, please contact nsuworks@nova.edu. 


\title{
Addressing Opioid Misuse and Abuse through Interprofessional Engagement and Education
}

\begin{abstract}
Purpose: The purpose of this initiative was to develop and implement an interprofessional panel aimed to expose a university audience to the magnitude of opioid misuse and abuse, as well as demonstrate each health professional's role in curbing the epidemic. Further, this experience was to provide a platform for interprofessional discussion and to share with attendees tangible action items to begin combatting the opioid epidemic.

Methods: An interdisciplinary committee of healthcare professionals collaborated to initiate a dialogue around opioid misuse and abuse to highlight the power of interprofessional (IP) collaboration in addressing the opioid epidemic. Each panel member shared a personal vignette about his or her professional experience with the epidemic, then the audience members were asked to participate in a question and answer session. Primary outcomes from this IP experience were derived from an eight-item satisfaction survey. The event was held in April 2016. The interdisciplinary committee marketed this event to all students, faculty, and staff in the Rueckert-Hartman College of Health Care Professionals one month before the event through electronic emails and posters.
\end{abstract}

Results: Forty-four (63\%) of participants completed the satisfaction survey of which $88.6 \%$ were students of healthcare professions. The satisfaction survey evaluative results were positive and referenced the panel as being an excellent IP event that was helpful, informative, and enjoyable. The results support that the initiative successfully increased understanding of the magnitude of the opioid epidemic for the attendees of this pilot event. The target audience of students expressed a greater awareness of the magnitude of the problem (43.2\%) and an increased appreciation of the IP aspects of opioid management strategies $(36.4 \%)$. Attendees also identified the need for ownership of their role as existing and future health care professionals and the need to work as an IP team to address the problem.

Conclusion: An interprofessional panel format as an optional extracurricular event is an effective way to communicate key educational messages about opioid misuse and abuse to a target audience of graduate students at a mid-sized college of health professions.

Author Bio(s)

Marta J. Brooks, PharmD, MS

Chair, Department of Pharmacy Practice, Associate Professor

School of Pharmacy, Rueckert-Hartman College for Health Professions, Regis University, Denver, Co.She is also a licensed pharmacist in the states of Connecticut, Texas, and Virginia.

Suzanne E. Holm, OTD, OTR, BCPR

Occupational Therapy Academic Program Coordinator, Assistant Professor

Rueckert-Hartman College for Health Professions, Regis University, Denver, CO.She is also a licensed OTR/ $L$ practitioner in the state of Colorado.

Shelene M. Thomas, PT, DPT, EdD, GCS

Assistant Professor, School of Physical Therapy, Rueckert-Hartman College for Health Professions, Regis University, Denver, $\mathrm{CO}$. She is also a licensed physical therapist practitioner in the state of Colorado. 
Amy J. Rich, PT, DPT, NCS

Assistant Professor, School of Physical Therapy, Rueckert-Hartman College for Health Professions, Regis University, Denver, CO. She is also a licensed physical therapist practitioner in the state of Colorado.

\section{Acknowledgements}

The authors thank the following individuals who contributed to the development and execution of this panel discussion: Roxanne England, MS, RN; Christine Feltman, PharmD; Ira Gorman, PT, DPT, PhD, MSPH, BA; Suzie Stolte; Joanna Stratton, PhD, LMFT, LP; and Rob Valuck, PhD, RPh. Funding was provided by Regis University Center for Teaching and Learning (CETL) for marketing and refreshment support. Finally, the authors recognize the University Provost, Janet Houser, PhD toward supporting this effort. 


\title{
IJAHSP \\ The Internet Joumnal of Allied Health Sciences and Practice \\ Dedicated to allied health professional practice and education
}

Vol. 16 No. 1 ISSN 1540-580X

\section{Addressing Opioid Misuse and Abuse through Interprofessional Engagement and Education: A Case Study of One University's Experience}

\author{
Marta J. Brooks, PharmD, MS \\ Suzanne E. Holm, OTD, OTR, BCPR \\ Shelene Thomas, PT, DPT, EdD, GCS \\ Amy J. Rich, PT, DPT, NCS \\ Regis University \\ United States
}

\begin{abstract}
Purpose: The purpose of this initiative was to develop and implement an interprofessional (IP) panel aimed at exposing a university audience to the magnitude of opioid misuse and abuse, as well as demonstrating each health professional's role in curbing the epidemic. This experience was to provide a platform for IP discussion and to share with attendees tangible action items to begin combatting the opioid epidemic. Methods: An interdisciplinary committee of healthcare professionals collaborated to initiate a dialogue around opioid misuse and abuse to highlight the power of IP collaboration in addressing this epidemic. Each panel member shared a personal vignette about his or her professional experience with the epidemic, then the audience members were asked to participate in a question and answer session. Primary outcomes from this IP experience were derived from an eight-item satisfaction survey. Results: Forty-four participants (63\%) completed the satisfaction survey of which $88.6 \%$ were students of healthcare professions. The satisfaction survey evaluative results were positive and referenced the panel as being an excellent IP event that was helpful, informative, and enjoyable. The results support that the initiative successfully increased understanding of the magnitude of the opioid epidemic for the attendees of this pilot event. The target audience of students expressed a greater awareness of the magnitude of the problem $(43.2 \%)$ and an increased appreciation of the IP aspects of opioid management strategies (36.4\%). Attendees also identified the need for ownership of their role as existing and future health care professionals and the need to work as an IP team to address the problem. Conclusion: An IP panel format as an optional extracurricular event is an effective way to communicate key educational messages about opioid misuse and abuse to a target audience of graduate students at a mid-sized college of health professions.
\end{abstract}

\section{INTRODUCTION}

\section{The Epidemic of Opioid Misuse and Abuse}

Prescription drug misuse and abuse are at epidemic levels with annual overdose deaths from opioid painkillers totaling approximately 28,647 nationally and 899 in Colorado in 2014..$^{1,2}$ In Colorado alone, $35 \%$ of all drug overdose deaths in 2013 were related to pharmaceutical opioids. ${ }^{3}$ As recently as five years ago, Colorado ranked second in the nation for self-admitted, non-medical use of prescription painkillers for young adults aged 12-24. ${ }^{4}$ Young adults, both college and university student populations, are of particular concern because the rates of substance abuse, including opioids and stimulates, are nearly three times higher than those found in people over age 25.5,6

With opioid overdoses at crisis levels, young adults are particularly vulnerable to non-medical prescription drug misuse and addiction, as well as those individuals seeking relief for moderate to severe pain. Opioids are frequently prescribed in cases of acute pain and post-surgical pain, and they have been overprescribed in both acute and chronic pain situations. ${ }^{7}$ To combat the deleterious effects of opioid abuse, the Institute for Medicine, the Centers for Disease Control and Prevention, and the Pain Management Society have made recommendations for practitioners to use a multimodal approach (e.g., psychotherapy, 
behavior modification, activity modification, electrical stimulation, massage therapy, and non-opioid medications) to treat pain.7,8,9 The implementation of the recommended multimodal approach requires collaborative practice by many health care practitioners in addition to the prescribing professional, including counseling, nursing, occupational therapy, pharmacy, physical therapy, psychology, and social work. These ongoing efforts are further supported by the Surgeon General call to action, Turn the Tide campaign, for healthcare providers. ${ }^{10}$ In addition, some students in medical professions (dentistry, nursing, medicine, and pharmacy) are calling for more addiction-related education than is being provided on opioid abuse and misuse.

Specific to Colorado, efforts are focused on prevention of the misuse of prescription pain medication through the Colorado Plan to Reduce Prescription Drug Abuse..$^{11}$ This program is designed to make Colorado the healthiest state in the nation and to systematically address the issues related to the over 255,000 Coloradans misusing prescription drugs ${ }^{11}$ The program focuses on expanding medication take-back programs, increasing public awareness about opioid use, and changing pain management guidelines. ${ }^{11}$ The key to the success of this Governor-lead initiative is the operational leadership of the Colorado Consortium for Prescription Drug Abuse Prevention (CCPDAP) which is helping to coordinate and implement recommendations and efforts to reduce prescription abuse as a statewide, inter-university, and inter-agency network. ${ }^{11}$

\section{The Role of Interprofessional Approaches and Education}

In preparation for the evolving interprofessional approach in health care practice, health profession students in educational settings are expected to learn about, from, and with each other through interprofessional education (IPE) initiatives. ${ }^{12}$ The Interprofessional Education Collaborative (IPEC) was formed to facilitate team-based healthcare approaches in health professions schools to optimize patient and healthcare outcomes, and to guide the various health care curricula nationwide. ${ }^{13}$ Formed in 2009, IPEC encouraged influential partnerships in the academic setting and outlined core competencies for interprofessional collaborative practice. However, due to its nascent history, outcome measures for these competencies have yet to be established and the extent and expectation of IPE remain unclear. ${ }^{14}$ Without a clear collective mandate for IPE by several individual professional education accreditation bodies, university initiatives have been sporadic in nature.

It is expected that IPE will continue to evolve due to the Patient Protection and Affordable Care Act of 2011 as it includes specific provisions for both team-based healthcare and education. ${ }^{15}$ With the intention of producing progressive healthcare graduates and leaders who are capable of understanding the changing healthcare landscape, Regis University, a coeducational Jesuit University in Denver, Colorado, has a focus to prioritize interprofessional collaboration. In the spirit of the IPEC organization and the interprofessional approach needed to address opioid misuse and abuse, this paper describes an interprofessional panel discussion designed to raise awareness of the need for collaboration to tackle the crisis of opioid misuse and abuse.

\section{DESCRIPTION OF PROCESS}

\section{Purpose}

The interprofessional panel aimed to 1) generate awareness among the university audience about the magnitude of opioid use, misuse, and abuse; 2) identify and facilitate opportunities between healthcare professionals and students to collaborate in preventing and combating this epidemic; and 3) create a sense of responsibility toward prevention of misuse and abuse of opioids in the attendees.

\section{Practice Description}

Regis University is a private, Jesuit institution in Denver, Colorado that has served students since 1877 and offers both undergraduate and graduate education with an enrollment of approximately 18,500 students. The University enrolls approximately 9,000 health care students in their graduate programs in the Rueckert-Hartman College for Health Professions (RHCHP) including Counseling and Family Therapy, Health Services Education, Nursing, inter-university Occupational Therapy, Pharmacy, and Physical Therapy. Within RHCHP, there are undergraduate programs in health and exercise science as well as health care administration.

\section{Healthcare Professional Initiatives/Guidelines}

In keeping with professional accreditation standards for inclusion of IPE for the health professions, RHCHP has implemented various interprofessional activities. Concurrent IPE at Regis includes but is not limited to a didactic/case-based ethics course, an interprofessional simulation lab and college-wide IPE days. Each school has included interprofessional guest lectures in courses. While RHCHP and the steering committee recognize that guest lectures are not interprofessional based on IPEC guidelines, the awareness of the various healthcare professional roles and their importance is valuable student learning.

(c) The Internet Journal of Allied Health Sciences and Practice, 2018 
Separately, each profession represented at Regis possess individualized strategies to intervene in the opioid epidemic as developed by their respective professional organizations. A detailed description of each professional association efforts is delineated in Table 1. The extent to which each profession has addressed opioid misuse and abuse in their respective curricula across the US is varied and beyond the scope of this article. It is tacitly understood that education on the topic is less than optimal.

Table 1. Regis University RHCHP Opioid Panel Healthcare Professions Represented and Associated Professional Association Opioid Initiatives

\begin{tabular}{|c|c|}
\hline Profession & Professional Association Initiatives/Guidelines/Initiatives \\
\hline Counseling & $\begin{array}{l}\text { Behavioral Health emphasizes the use of supportive psychotherapy, behavioral strategies, } \\
\text { and medication-assisted treatment to address opioid dependence and addiction. }{ }^{16} \\
\text { Comprehensive, whole-person therapies are designed to help the patient understand the } \\
\text { triggers for opioid misuse, develop strategies to effectively address underlying etiologies, } \\
\text { and incorporate healthy relationships and community in recovery. }\end{array}$ \\
\hline Nursing & $\begin{array}{l}\text { The American Nurses Association (ANA) is focusing nursing efforts on assessing, } \\
\text { diagnosing, and managing patients with addiction through the expansion of medication- } \\
\text { assisted treatment, training opioid prescribers, increasing the awareness of prescription drug } \\
\text { monitoring programs, increasing access to Naloxone, and in the development of abuse- } \\
\text { deterrent formulations. }{ }^{17}\end{array}$ \\
\hline Occupational Therapy & $\begin{array}{l}\text { Occupational therapy (OT) practice in pain management focuses on biopsychosocial } \\
\text { approaches to address occupational functioning, activity promotion, and self-management. } \\
\text { The American Occupational Therapy Association (AOTA) promotes consumer guidelines for } \\
\text { managing chronic pain and provides educational fact sheets on OT's role in pain } \\
\text { rehabilitation and substance abuse. }{ }^{18} \text { As part of the U.S. Surgeon General's call to action to } \\
\text { fight opioid abuse, AOTA and state OT associations are working to develop solutions to } \\
\text { address the opioid crisis. }{ }^{19}\end{array}$ \\
\hline Pharmacy & $\begin{array}{l}\text { The American Pharmacists Association }{ }^{\circledR} \text { has an Opioid Center designed to closely monitor, } \\
\text { respond, and inform their membership about opioid use, abuse, and misuse. Housed within } \\
\text { the practice section of the website, the opioid center provides tools and guidelines, clinical } \\
\text { and patient resources, as well as state and federal resources. }{ }^{20} \\
\text { The American Society of Health-System Pharmacists has a series of policy positions related } \\
\text { to stewardship of drugs with potential for abuse, controlled substance diversion and patient } \\
\text { access, naloxone availability, prescription drug abuse, and pain management. }{ }^{21} \text { Also, they } \\
\text { provide a formal statement regarding the role of pharmacist's in substance abuse prevention, } \\
\text { education, and assistance. }{ }^{22}\end{array}$ \\
\hline Physical Therapy & $\begin{array}{l}\text { The American Physical Therapy Association (APTA }{ }^{23} \text { is educating consumers about the } \\
\text { benefits of physical therapy as a safer alternative to opioids in their \#ChoosePT campaign } \\
\text { (moveforwardPT.com). }{ }^{24} \text { The APTA's Position Paper outlines what the profession is doing to } \\
\text { identify their role in pain management based on the Centers for Disease Control and } \\
\text { Prevention (CDC's) recommendations to move towards nonpharmacologic alternatives. }{ }^{25}\end{array}$ \\
\hline
\end{tabular}

(C) The Internet Journal of Allied Health Sciences and Practice, 2018 


\section{Methods}

An interdisciplinary faculty steering committee in RHCHP developed a proposal for a 90-minute pilot panel discussion around opioid misuse and abuse, as a grassroots effort to increase the awareness of campus students, faculty, and staff regarding opioid issues. The steering committee for the educational experience included members of the Schools of Pharmacy and Physical Therapy and an inter-university Occupational Therapy program within RHCHP at Regis University. The proposal was supported by the Academic Dean for RHCHP and Regis University's Center for Excellence in Teaching and Learning (CETL). CETL provided funding for this student-centered learning event.

For the pilot interprofessional panel discussion, panel members included Regis University faculty from various professions as well as representatives from the Colorado Consortium for Prescription Drug Abuse Prevention (CCPDAP) ${ }^{4}$ and the JP Prescription Drug Awareness Foundation. The JP Prescription Drug Awareness Foundation (JPPDAF) ${ }^{26}$ is a nonprofit organization that provides education about safe use, storage, and disposal of prescription medication and works with the Colorado Consortium to increase public awareness about opioid issues. The Director of the Consortium and Professor at the University of Colorado Skaggs School of Pharmacy and Pharmaceutical Sciences represented the CCPDAP on the panel. The RHCHP professions involved with the panel included counseling, nursing, occupational therapy (OT), pharmacy, and physical therapy (PT). Further details about the panel presenters are noted in Table 2. The setting for this interprofessional experience was a 115-seat classroom at RHCHP in April 2016. The panel was an extracurricular event that was intended for RHCHP student learning but was also open to all faculty and staff on the main campus in northwest Denver.

Table 2. Panel Members, Associated Credentials, and Vignette Description

\begin{tabular}{|c|c|c|}
\hline Role/Association & Experience & Vignette \\
\hline $\begin{array}{l}\text { Keynote speaker-opening } \\
\text { JP Prescription Drug } \\
\text { Awareness Foundation } \\
\text { representative }\end{array}$ & $\begin{array}{l}\text { Over } 20 \text { years in communications and public } \\
\text { relations for both for-profit and not for profit } \\
\text { organizations. Speaker lost her youngest } \\
\text { daughter to mixed drug toxicity in } 2011 \text {. }\end{array}$ & $\begin{array}{l}\text { Reviewed opioid epidemic including overdose } \\
\text { death rates nationally and in Colorado, with } \\
\text { statistics from the CDC, and costs associated } \\
\text { misuse/abuse. Closed with specifics on the } \\
\text { loss of her daughter to polysubstance abuse. }\end{array}$ \\
\hline $\begin{array}{l}\text { RHCHP } \\
\text { MS, RN } \\
\text { Instructor } \\
\text { School of Nursing }\end{array}$ & $\begin{array}{l}\text { Practicing clinician and educator with a focus } \\
\text { on mental health rotations. Currently teaches } \\
\text { across all programs in the nursing department } \\
\text { including traditional, accelerated, and } \\
\text { CHOICE; primary teaching responsibility } \\
\text { includes Mental Health Nursing Health } \\
\text { Promotion. Scholarly activities recently } \\
\text { presented at the American Association of } \\
\text { Occupational Health Nurses in } 2011 \text { called } \\
\text { Bridging Two Disciplines: Occupational Health } \\
\text { and Mental Health Nursing. }\end{array}$ & $\begin{array}{l}\text { Provided perspective on workplace misuse } \\
\text { and abuse highlighting the accessibility of } \\
\text { opioids to healthcare professionals and the } \\
\text { availability of resources to help individuals } \\
\text { with addiction. }\end{array}$ \\
\hline $\begin{array}{l}\text { RHCHP } \\
\text { PT, DPT, PhD, MSPH, BA } \\
\text { Associate Professor } \\
\text { School of Physical } \\
\text { Therapy }\end{array}$ & $\begin{array}{l}\text { Governor-appointed member of the Colorado } \\
\text { Commission for Affordable Health Care in } \\
2015 \text { and President of the Health Policy and } \\
\text { Administration Section of the APTA, leader on } \\
\text { policy in the Physical Therapy profession. }\end{array}$ & $\begin{array}{l}\text { Spoke to the impact of the epidemic on the } \\
\text { profession of PT sharing the ChoosePT } \\
\text { campaign for pain management. Included } \\
\text { information on policy and legislation that } \\
\text { happened under the Obama administration } \\
\text { regarding opioid misuse/abuse. }\end{array}$ \\
\hline $\begin{array}{l}\text { RHCHP } \\
\text { PharmD } \\
\text { Assistant Professor } \\
\text { School of Pharmacy }\end{array}$ & $\begin{array}{l}\text { Practicing pharmacist and executive team lead } \\
\text { for a major national chain for ten years before } \\
\text { joining Regis University. Experiential assistant } \\
\text { director and a member of the Interprofessional } \\
\text { Education Committee for RHCHP. }\end{array}$ & $\begin{array}{l}\text { Focused on personal experience dealing with } \\
\text { an over prescriber of opioids. Discussed } \\
\text { action steps including talking with the } \\
\text { physician, but ultimately turned the physician } \\
\text { in to legal authorities due to lack of action } \\
\text { towards the issues raised by the pharmacist. }\end{array}$ \\
\hline
\end{tabular}

(C) The Internet Journal of Allied Health Sciences and Practice, 2018 


\begin{tabular}{|c|c|c|}
\hline $\begin{array}{l}\text { RHCHP } \\
\text { OTD, OTR, BCPR } \\
\text { Assistant Professor } \\
\text { Creighton-Regis } \\
\text { Occupational Therapy } \\
\text { Program }\end{array}$ & $\begin{array}{l}\text { Practicing occupational therapist for over } 25 \\
\text { years in rehabilitation and acute care settings. } \\
\text { Occupational therapy Program Coordinator } \\
\text { and a member of the Interprofessional } \\
\text { Education Committee for RHCHP. Co-editor } \\
\text { and author of pain management chapter in OT } \\
\text { in Acute Care27 }\end{array}$ & $\begin{array}{l}\text { Shared insights into the role of Occupational } \\
\text { Therapy in helping clients develop strategies } \\
\text { to handle pain and still function in their day-to- } \\
\text { day lives. Addressed the emotional and } \\
\text { physical challenges related to pain and } \\
\text { completing activities of daily living. }\end{array}$ \\
\hline $\begin{array}{l}\text { RHCHP } \\
\text { PhD, LMFT, LP } \\
\text { Associate Professor } \\
\text { Division of Counseling and } \\
\text { Family Studies }\end{array}$ & $\begin{array}{l}\text { A Clinical Fellow and Approved Supervisor of } \\
\text { the American Association for Marriage and } \\
\text { Family Therapy. Member of } \\
\text { the Interprofessional Education Committee for } \\
\text { RHCHP and currently mentors research for } \\
\text { student research projects and } \\
\text { interprofessional collaboration. Lobbyist at the } \\
\text { state capital advocating for mental health } \\
\text { parity as well as continuing private practice in } \\
\text { two integrated primary care practice settings. }\end{array}$ & $\begin{array}{l}\text { Shared a story of a multigenerational family } \\
\text { dealing with issues of pain and opioid } \\
\text { misuse/abuse. Spoke to the emotional effect } \\
\text { of chronic pain on family relationships, coping } \\
\text { mechanisms, and the pervasive influence of } \\
\text { opioid addiction. }\end{array}$ \\
\hline $\begin{array}{l}\text { Featured speaker-closing } \\
\text { PhD, RPh } \\
\text { Coordinating Center } \\
\text { Director, Colorado } \\
\text { Consortium for } \\
\text { Prescription Drug Abuse } \\
\text { Prevention (CCPDAP) }\end{array}$ & $\begin{array}{l}\text { Founding Coordinating Center Director. } \\
\text { Clinical research interests include } \\
\text { pharmacoepidemiology (emphasis on } \\
\text { psychotropic medications); health services } \\
\text { research; evaluation of drug-related policy; } \\
\text { development, implementation, and evaluation } \\
\text { of computerized decision support systems for } \\
\text { optimization of prescribed pharmacotherapy; } \\
\text { drug utilization review; and drug formularies. } \\
\text { Recipient of numerous honors and awards. }\end{array}$ & $\begin{array}{l}\text { Provided additional statistics regarding the } \\
\text { magnitude of the opioid epidemic. Focused on } \\
\text { the Take Meds Seriously Campaign }{ }^{27} \text { from } \\
\text { CCPDAP which promotes Safe Use, Safe } \\
\text { Storage, and Safe Disposal of prescription } \\
\text { drugs. Provided handouts from the Take Meds } \\
\text { Seriously website: } \\
\text { http://takemedsseriously.org/28 }\end{array}$ \\
\hline
\end{tabular}

The interprofessional panel focused on the extent of opioid misuse and abuse, especially in Colorado. Specifically, through highlighting how the epidemic impacts each profession and identifying opportunities between healthcare professionals on how to collaborate effectively, students were empowered to recognize their role and responsibilities to influence this epidemic. The panel opened with a presentation from the JPPDAF that included epidemiological data on the epidemic and closed with a personal reflection by that panelist of her daughter's death related to prescription drug overdose. The next five panelists represented counseling, nursing, OT, pharmacy, and PT each of whom described a personal vignette on how opioid misuse and abuse has touched their practice (Table 2). Each vignette was a real-world example of the impact that opioid abuse/misuse including the pervasiveness of the disease across generations in families (counseling), the prevalence and impact of impaired practitioners (nursing), turning in a physician to the Drug Enforcement Administration (pharmacy), safer alternatives to opioids to manage pain (PT), and preventative, mind-body approaches to daily life skills management (OT). The panel ended with a brief presentation on safe use, storage, and disposal of opioids with a focus on how individuals in the audience can help, along with highlighting the numerous resources available via the CCPDAP. Time was allotted at the end for questions and answers. Several handouts highlighting the resources available on the website for CCPDAP were provided for attendees. The specific campaign highlighted was Take Meds Seriously ${ }^{27}$ which promotes Safe Use, Safe Storage, and Safe Disposal of prescription drugs which is easily implemented by all audience members regardless of healthcare profession or role as student or faculty.

The steering committee felt the topic was important to advertise to the entire campus community, however, aside from the posters that were displayed across campus and an announcement on the university intranet home page, the greatest awareness of the program was limited to the RHCHP building and associated word of mouth advertising. The deans for each school within RHCHP sent emails to their respective student, faculty, and staff populations encouraging attendance. The targeted number of attendees was set at 100, which included students, faculty, and staff. The target audience number was determined based on a number of factors which were not controlled by the steering committee (e.g., maximum seating allowance for the location ( $n=115)$, timing of the event during spring semester finals week, and time-sensitive funding availability for the event).

(C) The Internet Journal of Allied Health Sciences and Practice, 2018 


\section{EVALUATION MEASURE}

\section{Satisfaction Survey}

The pilot interprofessional opioid-focused panel was the first for the university and college of health professions. Therefore, it was decided to implement a straightforward eight-item anonymous satisfaction survey at the conclusion of the two-hour session. The survey included a combination of demographic information, as well as qualitative questions. Since the format of the panel was designed to be interprofessional, one of the qualitative questions centered on the structure of the program. Other qualitative questions included attendee's perspectives on topics addressed in the panel discussions: the magnitude of the problem, practitioner vignettes, and personal responsibility to make a difference, what could be improved to increase the effectiveness of the program in the future, and finally, considerations for future topics. Participant learning was qualitatively assessed with the following question: What did you gain from attending this discussion? The final question afforded the participant an opportunity to write in any other comments they wanted to share about the program.

Attendees voluntarily completed the survey that was placed at each seating location in the classroom and collected at the end of the program. One individual handled tabulation of the results, which were then reviewed by members of the steering committee. Given the pilot nature of the event and the timing, statistical analysis was not prospectively identified as a need for the initial panel event.

\section{RESULTS}

A total 70 participants (students and faculty) across professional programs within RHCHP, excluding the panel and steering committee members, were in attendance. Forty-four (63\%) participants completed the program satisfaction survey. Table 3 outlines the demographics of the attendees that completed a survey. Overall, the majority of participants and survey respondents $(88.6 \%)$ were students, which was the primary target population. There was representation from all professions within RHCHP except for the undergraduate program in Health and Exercise Science. The majority of student respondents were from the School of Physical Therapy (61.4\%). Other respondents included Occupational Therapy at $11.4 \%$, Pharmacy at $9.1 \%$, and Counseling at $4.5 \%$. Additionally, faculty comprised $11.4 \%$ of the attendees representing the Nursing, OT, Pharmacy, and PT programs ( $<5 \%$ of all faculty in the RHCHP). There were no attendees outside of RHCHP.

Table 3: Demographics of Program Evaluation Respondents

\begin{tabular}{|c|c|}
\hline \multicolumn{2}{|c|}{ What is Your Role } \\
\hline Student & 39 \\
\hline Faculty & 5 \\
\hline Staff & 0 \\
\hline \multicolumn{2}{|c|}{ What School or College Do You Attend } \\
\hline $\begin{array}{l}\text { Regis College, College of Business } \\
\text { and Economics, College of } \\
\text { Computer and Information } \\
\text { Sciences, College of Contemporary } \\
\text { Liberal Studies }\end{array}$ & 0 \\
\hline RHCHP & $44^{*}$ \\
\hline Counseling and Family Therapy & 2 (students) \\
\hline Health Services Education & 0 \\
\hline Nursing & 1 (faculty) \\
\hline Occupational Therapy & 5 (students) \\
\hline Pharmacy & 4 (students)/3 faculty \\
\hline Physical Therapy & 27 (students)/1 (faculty) \\
\hline
\end{tabular}


Table 4: Qualitative Questions

\begin{tabular}{|r|r|}
\hline What did you like most about the format? & \multicolumn{1}{|c|}{$(\mathbf{n}, \%)^{*}$} \\
\hline Outside Speakers & $37(84)$ \\
\hline Regis University Speakers & $29(65.9)$ \\
\hline Panel Discussion/Q\&A & $31(70.4)$ \\
\hline What did you think of the topics? & $(\mathbf{n}, \%)^{*}$ \\
\hline Magnitude of the problem & $30(68)$ \\
\hline Practitioner vignettes & $28(63)$ \\
\hline How you can help & $25(56.8)$ \\
\hline${ }^{*}$ A total of 44 respondents
\end{tabular}

Responses to qualitative questions are outlined in Table 4. For these questions, participants were asked to circle any answer that resonated with them. Therefore, the total number of responses is greater than the number of evaluations received. Results indicated a fairly even response to the three formats utilized in the program and the three topic areas covered by the panel (Table 4). Attendees rated the outside speakers as the most desirable aspect of the format of the program. Students rated the magnitude of the problem as the most highly rated topic. Attendees were also asked to identify what they gained from attending this forum. The subjective comments included that they gained a greater appreciation for the magnitude of the problem (43.2\%, which correlated with the most highly rated topic) and an increased appreciation of the interprofessional aspects in opioid management strategies (36.4\%). The top three results of the subjective question can be found in Table 5.

Table 5: Top 3 Responses to What Did You Gain from Attending this Discussion?

\begin{tabular}{|lc|}
\hline Response & (n, \%)* \\
\hline Appreciation for and understanding of the magnitude of the problem & $19(43.2)$ \\
\hline $\begin{array}{l}\text { Greater appreciation for the interprofessional aspects (perspectives, impact on, role in } \\
\text { management/treatment) }\end{array}$ & $16(36.4)$ \\
\hline Education (importance, approaches, materials/resources available, patient and practitioner) & $12(27.3)$ \\
\hline${ }^{*} \mathrm{~A}$ total of 52 responses from 44 respondents &
\end{tabular}

Respondents were also asked what topics would be beneficial to add to future discussions on opioid misuse and abuse. The general nature of the answers to this question tended to focus on the profession-specific requests (e.g., how can physical therapy treat someone with chronic pain or how can counseling be more effective). A wide range of topics were suggested, but many attendees requested taking the dialogue a step further by having a discussion about ways to treat and manage chronic pain and opioid abuse patients within the context of each of the professions represented. Finally, respondents were asked for feedback on what could be done to improve the effectiveness of the panel in the future. Attendees communicated a desire to include the perspectives of a physician, a patient, or a current student on the panel. Another requested topic was related to the specific drugs of abuse and the medications used to treat patients to help create more familiarity with the vernacular. Respondents also requested communicating this topic to the undergraduate population. A lengthier session and inclusion of a longer question and answer section were noted as areas for improvement in future programs. The evaluation left room for open-ended comments. The overwhelming majority (20/25 responses) referenced the panel as being an excellent interprofessional educational event that was helpful, informative, and enjoyable. 


\section{DISCUSSION}

Prescription medication misuse and abuse has become a nationally recognized epidemic and now requires attention at not only a societal level but also at an individual level. ${ }^{7}$ The interdisciplinary professionals involved in the creation of this interprofessional panel discussion aspired to take this information and disseminate it to a diverse group of individuals to challenge them to recognize the epidemic surrounding them and then take steps to address prevention in the future.

The steering committee had three specific aims in the creation of this pilot opioid panel discussion: 1) generate awareness among the university audience about the magnitude of opioid use, misuse, and abuse; 2) identify and facilitate opportunities between healthcare professionals and students to collaborate in preventing and combating this epidemic; and 3) create a sense of responsibility toward prevention of misuse and abuse of opioids in the attendees. The results of the eight-item satisfaction survey from this pilot panel discussion were overwhelmingly positive and supported achievement of each of these charges for the limited number of attendees of the event.

Attendees of the panel discussion consisted of students and faculty from various professions. The panel reached the intended main audience of healthcare professional students which demonstrates that the information presented was successfully disseminated to multiple healthcare students. However, there was a limited number of students overall with the majority being PT students. Faculty attendance was modest.

Speakers of the panel included the majority of professions in the RHCHP at Regis University as well as individuals from the community who demonstrate ongoing efforts to increase awareness of this crisis. The intent of this panel blend of Regis University faculty and members from the JPPDAF and CCDAP was to demonstrate to the audience the importance of an interprofessional and multi-stakeholder effort (University faculty, healthcare providers, non-profit organizations, and statewide entities). This intentional hybrid was selected to highlight and empower each audience participant toward a responsibility to prevent further prescription drug misuse and abuse. Results from the program evaluation revealed audience satisfaction with the opportunity to hear speaker vignettes from various perspectives and how each profession can address this epidemic individually and as a team. Audience participants also expressed satisfaction with the opportunity for a question and answer session designed to allow more in-depth questioning with particular individuals as well as group participation for problem-solving and critical thinking around how to promote appropriate use of opioids while preventing misuse and abuse.

Results of the satisfaction survey, as well as an open-ended comments portion, revealed three themes regarding what attendees obtained from this panel discussion. Participants agreed that this panel discussion increased awareness of the epidemic associated with prescription medicine abuse. Furthermore, participants identified that each individual has a personal responsibility and duty to address this epidemic as current and future healthcare professionals. The call to action to be a vital part of the solution and to address opioid misuse and abuse in a collaborative and cooperative manner was apparent. Audience participants felt the speakers helped them understand how their specific interprofessional role "looks" when addressing the problem of prescription drug misuse and abuse. The final theme that emerged was that all participants felt the urgency and responsibility to address this epidemic. They were given some tools to put this idea into practice (i.e., access to the Take Meds Seriously Campaign ${ }^{27}$ from CCPDAP which promotes Safe Use, Safe Storage, and Safe Disposal of prescription drugs). ${ }^{28}$

Although attendees were provided handouts and websites to utilize when contemplating taking the next step and spreading the word about this epidemic, many expressed the desire to do more. Both the JPPDAF and the CCPDAP presented additional resources and tools for the attendees to use to contribute further to community education on how to prevent prescription drug misuse and abuse.

\section{IMPLICATIONS}

The majority of participants expressed that this positive experience initiated a conversation between existing and future healthcare providers to prevent and combat the opioid epidemic. Results from the satisfaction survey reported a strength of this experience was the grassroots design which initiated interprofessional engagement in a university setting specifically related to opioid misuse and abuse. The literature supports the need for more development and assessment in interprofessional educational experiences which facilitate a richer interaction between existing and future healthcare providers. ${ }^{29}$ To this, current practitioner educators and clinicians should be mindful of the benefits of fostering interprofessional interactions and model such behaviors with students during their experiential (i.e., clinical or field work) rotations. Other attributes of a successful interprofessional educational experience include intentional reflection on the individual's professional role as well as interprofessional team role. Future direction for this IPE experience will include the use of a valid and reliable tool designed to

(c) The Internet Journal of Allied Health Sciences and Practice, 2018 
measure the impact of the educational experience for participants as well as the increased interaction, discussion, and reflection on how an interprofessional team can work to prevent and combat the opioid crisis.

\section{LIMITATIONS}

This event was conducted at one graduate-level, healthcare university in Denver, CO, USA as a pilot. Therefore, the pilot results may not be generalizable to all healthcare college and universities. Planning and implementing this project occurred within a limited timeframe (one month) due to funding constraints related to the university fiscal year end (April $30^{\text {th }}$ ) and notification of funding availability (i.e., approximately six weeks before fiscal year end). Therefore, the date of this event was scheduled during student finals week which the authors acknowledge was not ideal. Limited time and resources prevented extensive marketing of the panel discussion outside of RHCHP. Marketing to recruit individuals from all colleges across the university included posters and intranet announcements, but ultimately only members from RHCHP attended. The healthcare professional speakers asked to participate in the panel represented only those professions at RHCHP which caused the exclusion of physicians. None of the panel members were licensed to write a prescription for opiates, therefore opioid-prescribing healthcare professionals were not represented. The student attendee population was biased towards PT students and represented only a small proportion of the student body. Therefore, the evaluation results may not have adequately represented the other professions of RHCHP, especially nursing where there was no student representation based on the surveys returned. The disproportionate nature of the attendance could have been driven by individual school final exams and associated timing. Faculty representation, while present based on visual scanning of the audience, was not fully represented in the completed satisfaction surveys. The steering committee made every attempt to find a suitable time where the most students from all colleges and schools could attend. Also, approximately $40 \%$ of the respondents did not complete the survey which could account for additional or less well represented student professions and more faculty representation. Finally, the pilot panel event was considered an extracurricular event; it was designed to raise awareness of the need for interprofessional engagement to tackle the epidemic thus does not meet all the current standards for IPE.

\section{FUTURE DIRECTIONS}

From a real-world practice perspective, this pilot effort encourages students to learn more about, from, and with each other in the context of pain management and appropriate use of opioids. Future efforts should incorporate local practicing healthcare providers as part of the collaborative learning experience. As a result of the positive response from the attendees of this opioid panel discussion, the steering committee is fully committed to repeating the event annually, incorporating attendee feedback. Marketing tools will be expanded from posters placed around campus to use of social media, electronic notifications, and announcements during meetings across the university campus. The steering committee believes that with increased planning time to advertise the event, a greater cohort of individuals across all professions in RHCHP can be captured to attend this invaluable experience in the future. To further explore the perspective from a health care professional who can prescribe opioid medications, the steering committee plans to invite a nurse practitioner or another prescriber, to the panel discussion as well as provide the patient perspective (e.g., a person in recovery). With regards to learning about, from, and with each other through IPE, the steering committee intends to include more reflective time, group interactions, and validated evaluation tools to assess learning in future events. An effort will be made to find more action-oriented resources and tools for attendees to take out of the classroom and use with individuals in their community who are struggling with this epidemic. Finally, while not expressly stated in the evaluation feedback, the growing use of standing naloxone orders for overdose prevention and management will be included.

\section{CONCLUSION}

Opioid misuse and abuse is an epidemic that has captured the attention of governing bodies at a national and local level. ${ }^{10}$ Specifically, the state of Colorado has charged health care professionals to take responsibility and action to combat this epidemic. $^{3}$ This initiative falls directly in line with recommendations from the CDC. ${ }^{2} \mathrm{~A}$ common theme identified from these governing bodies is the need for an interprofessional approach to address opioid misuse and abuse. Healthcare professionals need to join as a team to combat prescription overdose deaths, an epidemic that is currently one in four of the most serious epidemics affecting the United States. ${ }^{3}$

Regis University strives to produce students that understand the importance of interprofessional collaboration to improve patient quality of care. There is no greater example of the ability of interprofessional collaborative care to contribute to the overall quality of care and address a societal need than through the prevention and reduction of opioid misuse and abuse. The results from the evaluation of the pilot interprofessional panel discussion support that this initiative was a start towards this goal. Overall, the target audience of students expressed satisfaction with the event and had a greater understanding of the magnitude of the

(C) The Internet Journal of Allied Health Sciences and Practice, 2018 
epidemic. More importantly, student attendees identified the need for ownership of their role as an existing or future health care professional to combat this epidemic and the need to work as an interprofessional team to address the problem.

\section{DECLARATION OF INTEREST}

The authors report no declaration of interest. The authors are responsible for writing and the content of this article.

\section{REFERENCES:}

1. Centers for Disease Control and Prevention [CDC]. Increases in drug and opioid overdose deaths - United States, 20002014. Available at http://www.cdc.gov/mmwr/preview/mmwrhtml/mm6450a3.htm?s_cid=mm6450a3_w. Accessed March 9, 2017.

2. Centers for Disease Control and Prevention [CDC]. Injury prevention and control: Opioid overdose. State data. Available at http://www.cdc.gov/drugoverdose/data/statedeaths.html. Accessed March 9, 2017.

3. Colorado Consortium. Consortium prescription drug abuse data dashboard. Available at http://www.corxconsortium.org/wpcontent/uploads/New-Prescription-Drug-Abuse-Data-Dashboard1.pdf. Accessed March 9, 2017.

4. Colorado Consortium. Available at http://www.corxconsortium.org/. Accessed March 9, 2017.

5. National Council on Patient Information and Education. Educate before you medicate. Available at http://www.talkaboutrx.org/documents/GetTheFacts.pdf.

6. Substance Abuse and Mental Health Services Administration. (2012). Results from the 2011 national survey on drug use and health: Summary of national findings. Office of Applied Studies, NSDUH Series H-44, HHS Publication No. (SMA) 124713. Rockville, MD. Available at http://www.samhsa.gov/data/nsduh/2k11results/nsduhresults2011.htm.

7. Colorado Plan to Reduce Prescription Drug Abuse. Available at https://www.colorado.gov/pacific/sites/default/files/PW_Colorado-Plan-to-Reduce-Prescription-Drug-Abuse_0.pdf. Accessed March 9, 2017.

8. Centers for Disease Control and Prevention [CDC]. CDC guideline for prescribing opioids for chronic pain - United States, 2016. Available at https://www.cdc.gov/mmwr/volumes/65/rr/rr6501e1.htm. Accessed March 9, 2017.

9. Institute of Medicine. Report from the Committee on Advancing Pain Research, Care, and Education: Relieving Pain in America, A Blueprint for Transforming Prevention, Care, Education and Research. Available at http://books.nap.edu/openbook. php?record_id=13172\&page=1. Accessed March 9, 2017.

10. Chou R, Fanciullo GJ, Fine PG, Adler JA, Ballantyne JC, et al. Clinical guidelines for the use of chronic opioid therapy in chronic noncancer pain. J Pain. 2009;10(2):113-30. [PMID: 19187889].

11. Surgeon General's Call to End the Opioid Crisis. Turn the Tide. Available at http://turnthetiderx.org/\# Accessed March 3, 2017.

12. Bainbridge L, Wood VI. The power of prepositions: A taxonomy for interprofessional education. J Interp Care. 2013;27(2):131-6. [PMID: 23030634].

13. World Health Organization (WHO). (2010). Framework for action on interprofessional education \& collaborative practice. Available at http://whqlibdoc.who.int/hq/2010/WHO_HRH_HPN_10.3_eng.pdf. Accessed March 9, 2017.

14. Interprofessional Education Collaborative (IPEC). What is Interprofessional Education (IPE)? Available at https://ipecollaborative.org/About_IPEC.html. Accessed March 9, 2017.

15. Zorek J, Raehl C. Interprofessional education accreditation standards in the USA: A comparative analysis. J Interp Care. 2013;27:123-30. [PMID: 22950791].

16. Substance Abuse and Mental Health Service Administration. Available at http://www.samhsa.gov/. Accessed March 9, 2017.

17. American Nurses Association. Nursing's Role in Addressing Nation's Opioid Crisis. American Nurses Association. Available at http://nursingworld.org/DocumentVault/GOVA/Health-System-Reform/Nursings-Role-Opioid-Crisis.pdf Accessed on March 9, 2017.

18. American Occupational Therapy Association. http://www.aota.org/ Accessed March 9, 2017.

19. American Occupational Therapy Association. Surgeon General calls on health care professionals to combat opioid abuse. 2016. Available at http://www.aota.org/Publications-News/AOTANews/2016/combat-opioid-use-epidemic-surgeongeneral.aspx

20. American Pharmacists Association. Opioid Center. Available at http://www.pharmacist.com/opioid-use-abuse-and-misuseresource-center. Accessed March 9, 2017.

21. ASHP Policy Positions, 1982-2016. Available at http://www.ashp.org/DocLibrary/BestPractices/ashp-policy-positions-19822016-word.docx - 1275k -. Accessed March 9, 2017.

(c) The Internet Journal of Allied Health Sciences and Practice, 2018 
22. ASHP Statement on the Pharmacist's Role in Substance Abuse Prevention, Education, \& Assistance. Available at http://www.ashp.org/DocLibrary/BestPractices/SpecificStSubstance.aspx. Accessed March 9, 2017.

23. American Physical Therapy Association (APTA). Available at http://www.apta.org. Accessed March 9, 2017.

24. American Physical Therapy Association. Move Forward. American Therapy Association. Available at http://www.moveforwardpt.com/Default.aspx. Accessed March 9, 2017.

25. American Physical Therapy Association. APTA Launches \#ChoosePT Campaign to Battle Opioid Epidemic.PT in Motion. Available at http://www.apta.org/PTinMotion/News/2016/6/7/ChoosePTCampaignLaunch/. Accessed March 9, 2017.

26. JP Prescription Drug Awareness Foundation. Available at http://www.jpawarenessfoundation.org/. Accessed March 9, 2017.

27. Holm SE. Pain management. In: Smith-Gabai H, Holm S, (Eds.), Occupational Therapy in Acute Care. Bethesda, MD: AOTA Press; 2017:673-83.

28. Take Meds Seriously. Available at http://takemedsseriously.org/ Accessed March 3, 2017.

29. Buring SM, Bhushan A, Broeseker A, Conway S, Duncan-Hewitt W, et al. Interprofessional Education: Definitions, Student Competencies, and Guidelines for Implementation. Am J Pharm Educ. 2009 Jul 10;73(4):59. [PMID: 19657492]. 